\title{
CFS hydroxylase cofactor levels in some neurological diseases
}

\author{
A C Williams, R A LeVINE,* T N CHASE, W lOVENBERG,* AND D B CALNE \\ From the Experimental Therapeutics Branch, IRP, National Institute of Neurological and Communicative \\ Disorders and Stroke, National Institutes of Health, Bethesda, Maryland
}

S U M M A R Y The cerebrospinal fluid concentration of hydroxylase cofactor has been measured in patients with Parkinson's disease, the Shy-Drager and Steele-Richardson syndromes, adult onset focal dystonia, essential tremor, Huntington's disease and presenile dementia. The results were compared with age matched controls and low values were demonstrated for all disease groups studied except for focal dystonia.

Tyrosine and tryptophan hydroxylation are the rate limiting steps for production of dopamine, norepinephrine and serotonin. ${ }^{1}$ There is good evidence that the availability of tetrahydrobiopterin $\left(\mathrm{BH}_{4}\right)$, the pterin cofactor for these reactions, is important in controlling the rate of this hydroxylation. ${ }^{23}$ This pterin is present in high concentrations in monoaminergic pathways, where it is probably synthesised intraneuronally. ${ }^{4}$ It is also present in other organs of the body and in serum but does not readily cross the blood-brain barrier. ${ }^{3}$ CSF hydroxylase cofactor content, predominantly consisting of $\mathrm{BH}_{4}$, therefore, may reflect levels in brain, probably with a large contribution from the aminergic neurons of the basal ganglia.

In a previous study 5 it was demonstrated that: (1) hydroxylase cofactor, which is predominantly composed of $\mathrm{BH}_{4}$, can be measured reliably in lumbar CSF; (2) levels are low in Parkinson's disease; and (3) levels correlate well with CSF homovanillic acid (HVA) content in both the normal population and in patients with Parkinson's disease. CSF hydroxylase cofactor levels therefore appear to reflect central aminergic activity and the study has now been extended to other diseases where disturbances of monoamine function are known or suspected.

*Section of Biochemical Pharmacology, National Heart, Lung and Blood Institute

Address for reprint requests: Adrian Williams, Building 10, Room 3D12, National Institutes of Health, Bethesda, Maryland 20205.

Accepted 11 April 1980
The disorders that have been investigated are Parkinson's disease, the Shy-Drager syndrome, the Steele-Richardson syndrome, adult onset focal dystonia, essential tremor, Huntington's disease, and presenile dementia.

\section{Methods}

Controls The control group consisted of patients who had no neurological or psychiatric disease and who were on no medication. Patient and control groups were age matched such that their mean ages were within 2 years of each other.

Patients The investigation involved 11 patients with Parkinson's disease, four patients with ShyDrager syndrome, seven patients with SteeleRichardson syndrome, eight patients with adult onset dystonia (usually manifested as torticollis), ten patients with essential tremor (five of them unrelated familial cases), eight patients with Huntington's disease, and eight patients with presenile dementia presumably due to Alzheimer's disease as all known causes of dementia were excluded. All patients were having a lumbar puncture for diagnostic purposes or as a prelude to experimental drug studies. No patients were taking any drugs and none had a history of high alcohol intake.

Procedure Patients and controls were placed cn a standard diet for 48 hours before the lumbar puncture. All were rested in bed for eight hours prior to the lumbar puncture which was performed between 0800 and 1000 hours. A standard aliquot of CSF was taken for the 
hydroxylase cofactor estimation and placed in a polypropylene tube in dry ice by the bedside. Samples were then transferred to a liquid nitrogen tank until the time of assay. Specimens were not studied if their protein concentration or cell count was abnormal.

Assay Hydroxylase cofactor was estimated by a modification of a previously described radioenzymatic method. ${ }^{6}$ This method, which utilises a phenylalanine hydroxylation system, was altered to obtain the necessary sensitivity for CSF assay. ${ }^{5}$

\section{Results}

The CSF hydroxylase cofactor values obtained are shown in the table and the figure.

Patients with Parkinson's disease, the ShyDrager syndrome, the Steele-Richardson syndrome, essential tremor, Huntington's disease and presenile dementia all had abnormally low values compared with their age matched controls ( $\mathrm{p}<0.01$ by unpaired ' $t$ ' test). The patients with focal dystonia had normal levels.

\section{Discussion}

The critical role for $\mathrm{BH}_{4}$ for the synthesis of
Table $\mathrm{BH}^{4}$ values in all disease groups compared with their age matched controls

\begin{tabular}{lcl}
\hline & $B H_{4}$ value $\pm S E$ & $\begin{array}{l}\text { BH } 4 \text { value } \pm S E \\
\text { for aged matched } \\
\text { controls }\end{array}$ \\
\hline Parkinson's disease & $9 \cdot 1 \pm \cdot 7$ & $17 \cdot 5 \pm 1 \cdot 3(\mathrm{n}=13)$ \\
Shy-Drager syndrome & $4 \cdot 5 \pm 1 \cdot 2$ & $17 \cdot 5 \pm 1 \cdot 3(\mathrm{n}=13)$ \\
Steel-Richardson syndrome & $8 \cdot 5 \pm 1 \cdot 1$ & $17 \cdot 5 \pm 1 \cdot 3(\mathrm{n}=13)$ \\
Pre-senile dementia & $7 \cdot 8 \pm 1 \cdot 7$ & $17 \cdot 5 \pm 1 \cdot 3(\mathrm{n}=13)$ \\
Huntington's disease & $10 \cdot 7 \pm 1 \cdot 3$ & $17 \cdot 5 \pm 1 \cdot 3(\mathrm{n}=13)$ \\
Essential Tremor & $10 \cdot 0 \pm 1 \cdot 4$ & $19 \cdot 3 \pm 1 \cdot 7(\mathrm{n}=10)$ \\
Focal dystonia & $15 \cdot 6 \pm 2 \cdot 2$ & $19 \cdot 3 \pm 1 \cdot 7(\mathrm{n}=10)$ \\
\hline
\end{tabular}

dopamine, coupled with the low CSF values previously demonstrated in Parkinson's disease, ${ }^{5}$ raises the question of whether a defect in $\mathbf{B H}_{4}$ production, developing in adult life, could be the primary metabolic defect in idiopathic parkinsonism. This hypothesis was given some credence by the recent finding that certain forms of phenylketonuria, associated with severe defects in brain dopamine production, were caused by metabolic defects resulting in low levels of available $\mathrm{BH}_{4} \cdot{ }^{78}$ However, in this study we have shown that low hydroxylase cofactor levels are not specific to Parkinson's disease, but also occur with the parkinsonism associated with the Shy-Drager and Steele-Richardson syndromes. This nonspecificity of reduced hydro-

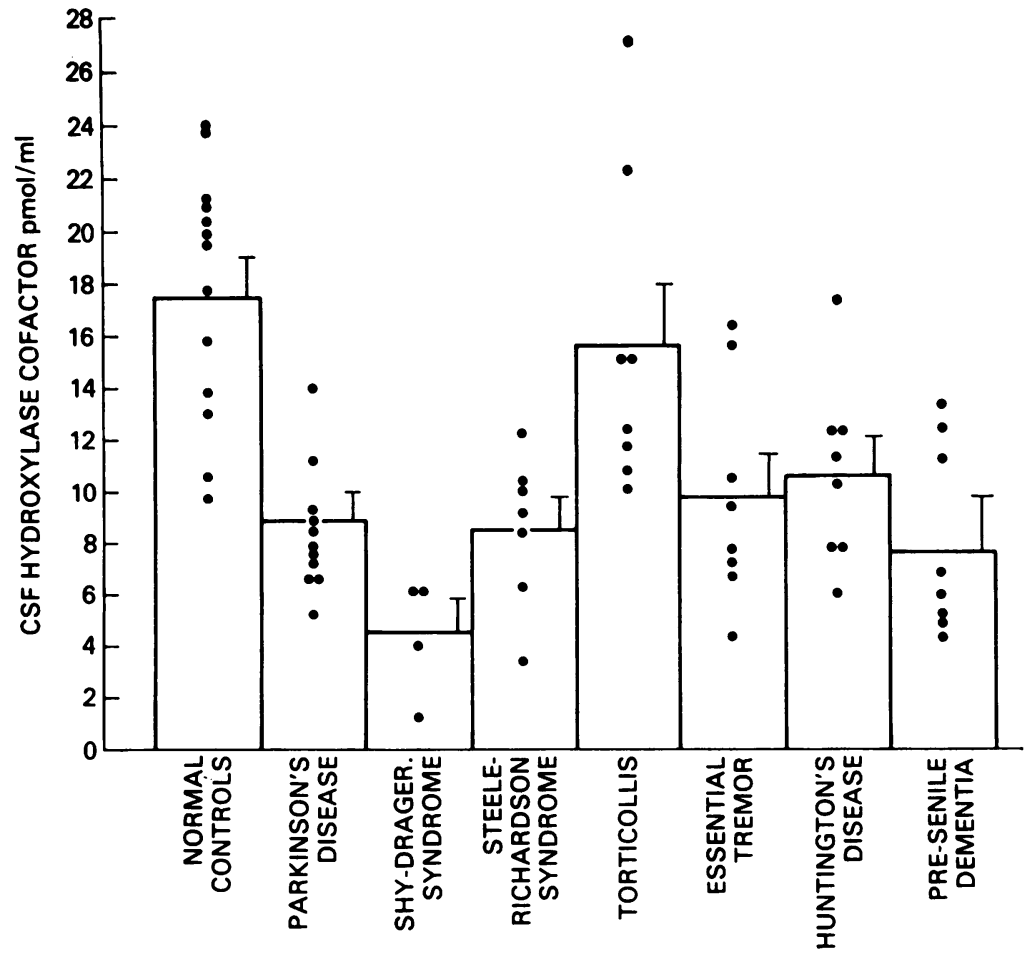

Figure Hydroxylase cofactor levels in the lumbar CSF of patients with some neurological diseases. The mean values and standard errors for each group are indicated. 
xylase cofactor levels, the overlap of parkinsonian values with the normal range, and the normal serum levels in Parkinson's disease ${ }^{9}$ together indicate that a defect in $\mathrm{BH}_{4}$ synthesis is unlikely to be a primary metabolic defect. The low concentration of CSF hydroxylase cofactor in these disorders is more likely to be due to loss of aminergic neurons from an unidentified cause.

The pathophysiology of dystonia has long been suspected to involve dopaminergic mechanisms. The basis for this view has been pharmacological, as some patients respond to dopaminergic agents, ${ }^{10}$ and dopamine receptor blocking agents can cause dystonia acutely. ${ }^{11}$ Limited studies on ventricular CSF have led to reports of a modest reduction of HVA in adult onset dystonia, ${ }^{12}$ but concentrations of HVA in the lumbar CSF are normal; ${ }^{13}$ there is no information on tissue levels in brain. The normal values of CSF hydroxylase cofactor found during this study in patients with focal dystonia do not support a hypothesis of disordered dopaminergic function in this form of dystonia, although an anatomically localised disturbance at either pre-synaptic or post-synaptic level cannot be excluded. This is in contrast to preliminary observations on one family with hereditary generalised dystonia where low hydroxylase cofactor levels have been noted. ${ }^{14}$

Essential tremor is inherited as a dominant gene in about $50 \%$ of cases but has no known pathological basis. ${ }^{15}$ Physiological and pharmacological studies suggest that a central disturbance, possibly involving norepinephrine, is involved. ${ }^{16}$ There is no convincing relationship between essential tremor and Parkinson's disease although some authors have commented on mild parkinsonian features in some patients, and the earliest tremor demonstrable in patients with Parkinson's disease is often more like an essential tremor than the classical pill-rolling tremor which develops later. ${ }^{17}$ Neurochemical studies have not hitherto been undertaken in this disorder so the detection of low hydroxylase cofactor levels in the CSF is of interest. It is possible that the low levels reflect an underactive dopaminergic system, but further studies are needed because the low values could also derive from underactivity in serotonergic or noradrenergic systems. There must be different mechanisms involved than those responsible for Parkinson's disease because the disorders are so dissimilar clinically and pharmacologically.

In all the diseases so far discussed, the patients had mild or moderate disease without evidence of cerebral atrophy on computed tomography. In Huntington's disease, and more particularly in the presenile dementias, cerebral atrophy is usually present. This complicates the interpretation of CSF neurochemistry because of a dilution effect consequent upon compensatory enlargement of the subarachnoid space. There is no satisfactory way of correcting for this problem; however, the degree of atrophy in our Huntington's disease patients was slight and several of the patients had low levels of hydroxylase cofactor without evidence of atrophy. The low concentration of hydroxylase cofactor in Huntington's disease would be in accord with previous studies showing low HVA levels in cerebrospinal fluid. ${ }^{18}$ Dopamine and HVA concentrations in brain are normal ${ }^{19}$ in this disease, but these are measured in relation to tissue protein or neurotransmitters other than dopamine, and do not exclude reduction in the total amount of dopamine metabolism.

The results in the presenile dementia group have to be treated with more caution, as all patients had significant cerebral atrophy. However, it is probably that they partially reflect decreased monoaminergic function in this disease, although cholinergic systems may be preferentially involved. ${ }^{20}$ It is of some interest that low $\mathrm{BH}_{4}$ levels in brain have been found in experimental animals with aluminum intoxication, ${ }^{21}$ a suspected factor in the aetiology of Alzheimer's disease. ${ }^{22}$

\section{References}

1 Lovenberg W, Ames MM, Lerner P. Mechanisms of short-term regulation of tyrosine hydroxylase. In: Lipton MA, DiMascio A, Killam KF, eds. Psychopharmacology: A Generation of Progress. New York: Raven Press, 1978: 247-59.

2 Brenneman AR, Kaufman $S$. The role of tetrahydropteridines in the enzymatic conversion of tyrosine to dopa. Biochem Biophys Res Comm 1964; 17:177-83.

3 Kettler R, Bartholini G, Pletscher A. In vivo enhancement of tyrosine hydroxylation in rat striatum by tetrahydrobiopterin. Nature 1974; 249:476-8.

4 Bullard WP, Guthrie PB, Russo PB, Mandell AJ. Regional and subcellular distribution and some factors in the regulation of reduced pterins in rat brain. J Pharmacol ExP Ther 1978; 206:4-20.

5 Lovenberg W, Levine RA, Robinson D, Williams AC, Calne DB. Hydroxylase cofactor activity in cerebrospinal fluid of normal subjects and patients with Parkinson's disease. Science 1979; 204:624-6.

6 Guroff G, Rhoads CA, Abromowitz A. A simple 
radioisotope assay for phenylalanine hydroxylase cofactor. Anal Biochem 1967; 21:273-8.

7 Kaufman S, Holtzman NA, Milstien S, Butler i, Krumholz A. Phenylketonuria due to deficiency of dihydropteridine reductase. $N$ Engl J Med 1975; 293:785-90.

8 Kaufman S, Berlow S, Summer G et al. Hyperphenylalinemia due to a deficiency of biopterin. $N$ Engl J Med 1978; 299:673-9.

9 Leeming RJ, Blair JA, Melikian V, O'Gorman DJ. Biopterin derivatives in human body fluids and tissues. J Clin Path 1976; 29:444-51.

10 Coleman M. Preliminary remarks on the L-dopa therapy of dystonia. Neurology 1970; 20:114-21.

11 Ayd FJ. A survey of drug-induced extrapyramidal reactions. J Amer Med Assn 1961; 175: 1054-60.

12 Tabaddor K, Wolfson LI, Sharpless NS. Diminished ventricular fluid dopamine metabolites in adult onset dystonia. Neurology 1978; 28:1254-8.

13 Chase TN. Biochemical and pharmacological studies of dystonia. Neurology 1970; 20:122-30.

14 Williams AC, Eldridge R, Levine R, Lovenberg W, Paulson GW. Low CSF hydroxylase cofactor in inherited dystonia. Lancet (in press).

15 Larsson $T$, Sjogren $T$. Essential tremor. A clinical and genetic population study. Acta Psychiat Neurol Scand 1960; 36:1-176.
16 Morgan MH, Hewer RL, Cooper R. Effect of the beta-adrenergic blocking agent propranolol on essential tremor. J Neurol Neurosurg Psychiatry 1973; 36:618-21.

17 Lance JW, Schwab RS, Peterson EA. Tremor and the cog-wheel phenomenon in Parkinson's disease. Brain 1963; 86:95-110.

18 Chase TN. Biochemical and pharmacologic studies of monoamines in Huntington's chorea. In: Barbeau A, Chase TN, Paulson GW, eds. Advances in Neurology, Vol 1, Huntington's Chorea 1872-1972. New York: Raven Press, 1973: 533-42.

19 Bird ED, Iversen LL. Huntington's chorea: postmortem measurement of glutamic acid decarboxyylase, choline acetyltransferase and dopamine in basal ganglia. Brain 1974; 97:457-72.

20 Davies P, Maloney AJF. Selective loss of central cholinergic neurons in Alzheimer's disease. Lancet 1976; 2:1403.

21 Leeming RJ, Blair JA. Dialysis dementia, aluminum and tetrahydrobiopterin metabolism. Lancet 1979; 1:556.

22 Crapper DR, Krishnan SS, Dalton AJ. Brain aluminum distribution in Alzheimer's disease and experimental neurofibrillary degeneration. Science 1973; 180:511-3. 